2010

\title{
The Aerodynamics of Frisbee Flight
}

Kathleen Baumback

University of South Florida

\author{
Advisors: \\ Masahiko Saito, Mathematics and Statistics \\ Scott Campbell, Chemical \& Biomedical Engineering \\ Problem Suggested By: Scott Campbell
}

Follow this and additional works at: https://digitalcommons.usf.edu/ujmm

Part of the Mathematics Commons

UJMM is an open access journal, free to authors and readers, and relies on your support:

Donate Now

\section{Recommended Citation}

Baumback, Kathleen (2010) "The Aerodynamics of Frisbee Flight," Undergraduate Journal of Mathematical Modeling: One + Two: Vol. 3: Iss. 1, Article 19.

DOI: http://dx.doi.org/10.5038/2326-3652.3.1.31

Available at: https://digitalcommons.usf.edu/ujmm/vol3/iss1/31 


\title{
The Aerodynamics of Frisbee Flight
}

\begin{abstract}
This project will describe the physics of a common Frisbee in flight. The aerodynamic forces acting on the Frisbee are lift and drag, with lift being explained by Bernoulli's equation and drag by the Prandtl relationship. Using V. R. Morrison's model for the 2-dimensional trajectory of a Frisbee, equations for the $x$ - and $y$-components of the Frisbee's motion were written in Microsoft Excel and the path of the Frisbee was illustrated. Variables such as angle of attack, area, and attack velocity were altered to see their effect on the Frisbee's path and to speculate on ways to achieve maximum distance and height.
\end{abstract}

\section{Keywords}

Frisbee Flight, Aerodynamics, Trajectory

Creative Commons License

(c) (i) (\$)

This work is licensed under a Creative Commons Attribution-Noncommercial-Share Alike 4.0 License.

\section{Erratum}

This article was previously called Article 31. 


\section{TABLE OF CONTENTS}

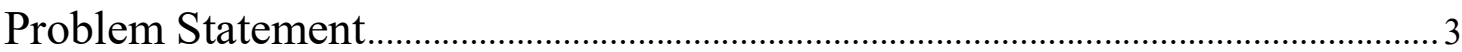

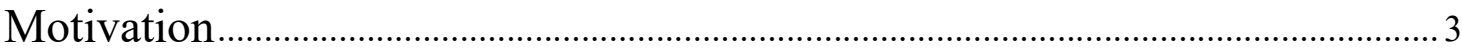

Mathematical Description and Solution Approach …............................................. 4

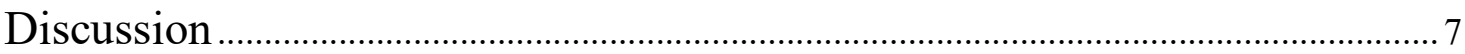

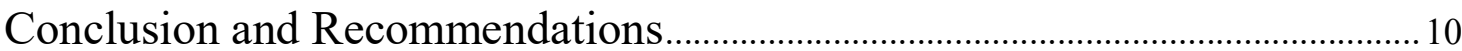

Nomenclature

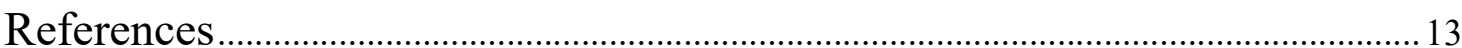

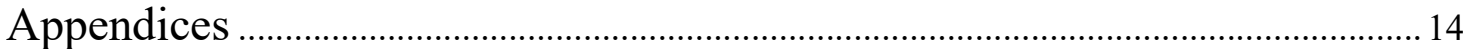




\section{PROBLEM STATEMENT}

The purpose of this study is the view the two-dimensional trajectory of a standard Frisbee using the equations for aerodynamic forces and by reconstructing a previous model, with a few modifications.

\section{Motivation}

Frisbee-tossing has been the popular pastime of many children and college kids across the U.S. and Canada since its invention by Fred Morrison in the 1950s. Even today, the popularity of the sport of Ultimate Frisbee continues to grow; according to the Ultimate Player's Association, it is played in more than 42 countries by hundreds of thousands of people.

A Frisbee is a flying disc that not only travels great distances when flung, but appears to hover in the air. Many have wondered at the physics behind the strange trajectory of the disc, assuming that its spin might be responsible for its lift. This is not the case-if someone were to spin a Frisbee without actually throwing it, the Frisbee would not lift itself, but simply drop to the ground. However, spin does provide a Frisbee with the necessary stability to continue on its path. Motoyama (2002) provides a full explanation of gyroscopic stability and how it keeps a Frisbee from flipping over.

This project is more focused on the Frisbee's trajectory. Although Frisbee motion is not immediately applicable to engineering, it is still important to understand the aerodynamic concepts behind its flight. Morrison (2005) wrote a Java code plotting and predicting the path of a Frisbee. My goal is to reproduce and test his equations in Microsoft Excel, and to correct errors 
if possible. I will also make suggestions for reaching the maximum height and distance and increasing flight time.

\section{MATHEMATICAL DESCRIPTION AND SOLUTION APPROACH}

The aerodynamic forces acting on the Frisbee involve the lift and drag forces. The forces in the y-direction are those of gravity and lift. Lift generally opposes gravity. According to the Kutta condition (Hummel), the Frisbee's shape causes the air above and underneath it to be deflected downward with a positive angle of attack. This forces the air flowing above the Frisbee to travel faster than the air below it. Furthermore, the Bernoulli Principle states that the pressure in a fluid decreases as the speed of the fluid increases, accounting for the lower pressure on the top of the Frisbee than on the bottom. This allows the Frisbee to hover temporarily before the disc is overcome by gravity.

Morrison derives the lift force from the Bernoulli Equation, giving

$$
F_{L}=\frac{1}{2} \rho v_{x}^{2} A C_{L}
$$

where $\rho$ is the density of the fluid, which we assume to be the density of air at sea level $1.23 \mathrm{~kg} /$ $\mathrm{m}^{3}$. The velocity of the Frisbee is represented by $v$, and the average throw is initially $14 \mathrm{~m} / \mathrm{s} . \mathrm{A}$ is the area of the Frisbee; since the diameter of a standard Frisbee is $0.26 \mathrm{~m}$, its area is $0.0531 \mathrm{~m}^{2}$. These numbers are provided by Morrison.

The lift coefficient $C_{L}$ is given by

$$
C_{L}=C_{L_{0}}+C_{L_{\alpha}} \alpha
$$


where $\alpha$ is the angle of attack in radians (Hummel). $C_{L}$ is a linear function of angle of attack, where $C_{L_{0}}$ is the y-intercept when $\alpha=0$, and $C_{L_{\alpha}}$ is the slope of the graph. According to Morrison, $C_{L_{0}}$ and $C_{L_{\alpha}}$ depend on the physical properties of the Frisbee. Therefore, for a Frisbee with fixed dimensions and mass, lift depends upon the angle of attack. For Morrison, $C_{L_{0}}$ is equal to 0.15 and $C_{L_{\alpha}}$ is 1.4 .

Acting in the negative-y direction is the gravitational force, which is given by

$$
F g=-m g
$$

The mass of a standard Frisbee is $0.175 \mathrm{~kg}$ and the acceleration due to gravity is $9.81 \mathrm{~m} / \mathrm{s}^{2}$.

The drag acts opposite and parallel to velocity, slowing the disc. The Prandtl relationship was chosen to calculate the drag force, which is

$$
F_{D}=-\frac{1}{2} C_{D} \rho A v_{x}^{2}
$$

The drag coefficient, $C_{D}$, is normally dependent upon three things: the Reynolds number, the spin parameter, and the angle of attack (Hummel, 2003). In our case, however, previous tests by Potts and Crowther (2002) have shown that the drag coefficient is independent of the Reynolds number, and that the spin parameter has a negligible effect. The drag coefficient is given by

$$
C_{D}=C_{D_{0}}+C_{D_{\alpha}}\left(\alpha-\alpha_{0}\right)^{2}
$$

$C_{D_{0}}$ is the form drag and $C_{D_{\alpha}}$ is the induced drag (Hummel, 2003). The form drag is the minimum drag due to skin friction and pressure drag, which Morrison takes to be 0.08 . The induced drag varies with lift, and is equal to 2.72 in this case. $\alpha_{0}$ is the angle of attack that produces the least lift, and is equal to $-4^{\circ}$ for most Frisbees. 
In order to test Morrison's model of a Frisbee in flight, his method was reproduced using Microsoft Excel. Seven columns were created: one for time, and one each for the $x$ - and $y$ components of position, velocity, and acceleration. See Table 2 in Appendix B for details.

The initial conditions were given by Morrison. Alongside those numbers stated above, the initial $y$-position, or the height at which the thrower released the Frisbee, was taken to be $1 \mathrm{~m}$, and the initial $x$-position (distance) was $0 \mathrm{~m}$. The initial $x$-and $y$-components of velocity were calculated using trigonometric functions once the angle of attack was given:

$$
\begin{gathered}
v_{x, i}=v_{i} \cos (\alpha)=14 \cos (\alpha), \\
v_{y, i}=14 \sin (\alpha) .
\end{gathered}
$$

Finally, initial $x$-component of acceleration was calculated as the drag force divided by mass:

$$
a_{x, i}=\frac{F_{D}}{m}=-\frac{1}{2 m} C_{D} \rho A v_{x}^{2}
$$

The $y$-component of acceleration was the difference between the lift force and gravity, both divided by mass:

$$
a_{y, i}=\frac{F_{L}-F_{g}}{m}=\frac{1}{2 m} C_{L} \rho A v_{x}^{2}-g
$$

Once the initial conditions were set, the motion of the Frisbee was plotted until the $y$ component of the Frisbee reached 0, with time intervals of $0.001 \mathrm{~s}$. The changes in position, velocity and acceleration were approximated by Excel via Euler's method:

$$
f^{\prime}(t) \approx \frac{f(t+\Delta t)-f(t)}{\Delta t} \Rightarrow f(t+\Delta t) \approx f(t)+\Delta t \cdot f^{\prime}(t)
$$

Therefore, 


$$
x \approx x_{\text {previous }}+\Delta t \cdot x_{\text {previous }}^{\prime}
$$

where $x^{\prime}$ is simply stated as:

$$
x^{\prime}=v_{x}
$$

The components $y, v_{x}$, and $v_{y}$ were also calculated using Euler's method, where $y^{\prime}, v_{x}{ }^{\prime}$, and $v_{y}{ }^{\prime}$ are described below:

$$
\begin{aligned}
& y^{\prime}=v_{y}, \\
& v_{x}^{\prime}=a_{x}, \\
& v_{y}^{\prime}=a_{y} .
\end{aligned}
$$

Changes in acceleration were calculated using the same aerodynamic equations used for initial conditions, varying only with $v_{x}$. An example of the spreadsheet can be found in Table 2 in the Appendix.

\section{DISCUSSION}

Morrison's results show that the Frisbee reaches a maximum height of about $1.5 \mathrm{~m}$ and a distance of $23 \mathrm{~m}$ when thrown at an angle of $5^{\circ}$. When his experiment was reproduced in Microsoft Excel, the Frisbee again reached a height of $1.5 \mathrm{~m}$; however, it only traveled a distance of $16.35 \mathrm{~m}$.

There is one possible reason for this discrepancy. In his appendix, the $x$-acceleration defined in Morrison's Java not omits the $\frac{1}{2 m}$ term. Copying his equation in the appendix yields a graph with a distance of $26 \mathrm{~m}$ and a height of $1.9 \mathrm{~m}$. Unfortunately, this graph deviates even farther from Morrison's; it is likely that this is simply a typing error. There is more inconsistency 
with Morrison's value for $C_{L 0}$; in his report, it is 0.1 , but in his appendix, it is 0.15 -again, however, this does not improve my results. Due to these errors, it is safe to assume that there were some in his simulation and that his results may be unreliable.

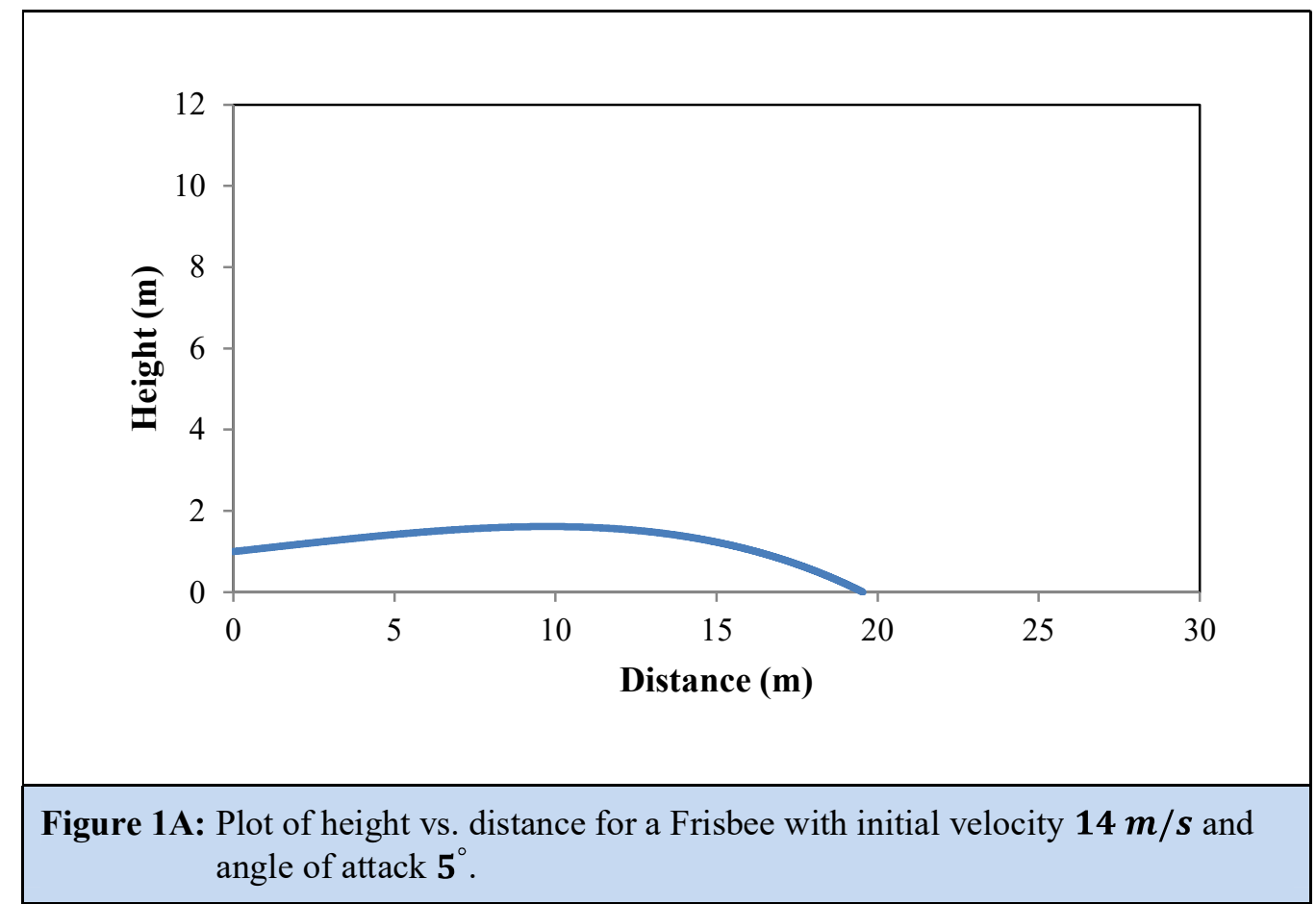

A more likely reason that the results are inconsistent is because Euler's method was used for position and velocity. Morrison describes changes in position and velocity as follows:

$$
\begin{gathered}
\Delta x=v_{x} \Delta t, \\
\Delta y=v_{y} \Delta t, \\
\Delta v_{x}=a_{x} \Delta t, \\
\Delta v_{y}=a_{y} \Delta t
\end{gathered}
$$


These equations were not used because they did not seem to work well in Excel, and it made more sense to set change in position equal to velocity, change in velocity equal to acceleration, etc., because that is their definition.

The model was tested using several different angles of attack ranging from $5^{\circ}$ to $45^{\circ}$. Some of the resulting graphs are displayed in the Appendix below. The maximum distance of $26.36 \mathrm{~m}$ was reached at an angle of attack of $10^{\circ}$, which is close to Morrison's results. At $11^{\circ}$, the distance recedes back to $26.23 \mathrm{~m}$.

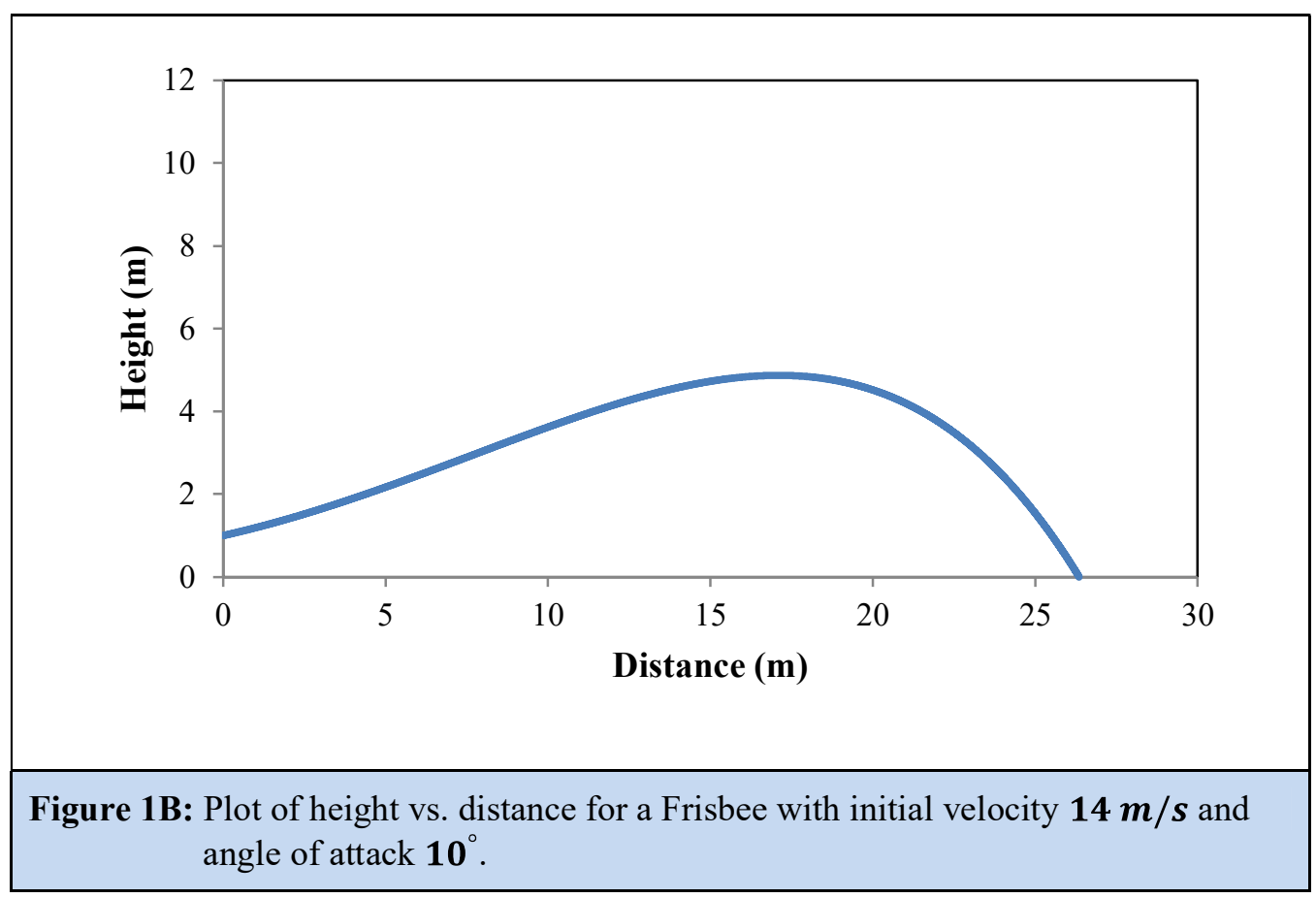

This may seem somewhat counterintuitive because the maximum distance of a projectile should be reached when launched at an angle of $45^{\circ}$. This is normally true because of the compromise between the $x$-and $y$-components of displacement. However, this is not the case; as the angle of attack increases, the drag coefficient increases, thus creating a larger drag force. The combination of an increased lift and drag causes the Frisbee to travel very high but drop quickly. 


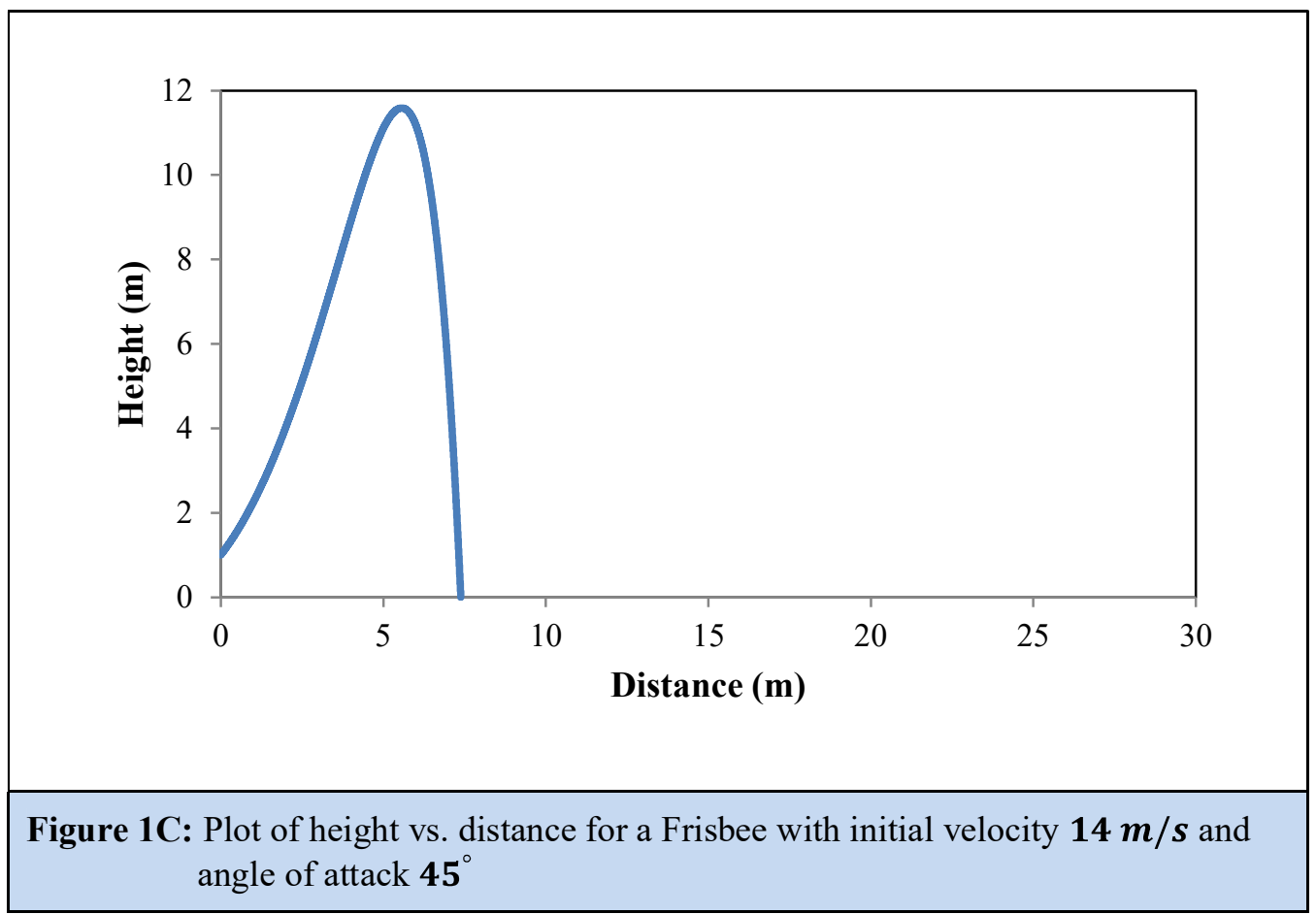

Using a constant angle of attack of $10^{\circ}$, the model was then tested using Frisbee diameters of $0.22 m, 0.24 m, 0.28 m$, and $0.3 m$. The Frisbee's height was shown to increase with diameter, whereas distance and flight time did not increase significantly; this is because the increase in area also increased both the drag and lift forces. Finally, the model was tested using different initial velocities. Increasing the initial velocity increased the distance, height, and flight time of the Frisbee, which is consistent with Morrison.

\section{CONCLUSION AND RECOMMENDATIONS}

A model for the trajectory of a standard Frisbee was done by Morrison using a Java program and reproduced here in Microsoft Excel with a few changes. The aerodynamic forces were used to calculate and view the two-dimensional path of a Frisbee in ideal conditions. The modification made to Morrison's model was Euler's method, which was used to calculate the changes in 
position and velocity. Certain parameters were then altered to see their effects on distance and height. The angle of attack which yielded the greatest distance was $10^{\circ}$; throwing the Frisbee at any greater angle resulted in a higher trajectory but no greater distance. As area increased, height also increased, and as velocity increased, both distance and height increased. This data suggests that the farthest flying Frisbee is simply one launched at $10^{\circ}$ at a great velocity.

The model was retested for varying masses of the Frisbee (Appendix A - Fig. 3A, 3B, and 3C): when mass increased, flight time decreased; however, when area also increased with mass, flight time increased greatly. If the increased diameter of the Frisbee were not a concern, this could be an alternative. Wind interference would be another thing to consider.

For now, the Frisbee remains the object of a beloved sport, and the ability to predict its path (with respect to angle of attack) could be of great use to Ultimate players. 


\section{NOMENCLATURE}

\begin{tabular}{|clc|}
\hline Symbol & Description & Unit \\
\hline$\rho$ & Air density & $\mathrm{kg} / \mathrm{m}^{3}$ \\
\hline$C_{D}$ & Area of Frisbee & $\mathrm{m}^{2}$ \\
\hline$C_{L}$ & Lift coefficient & - \\
\hline$C_{D 0}$ & Form drag coefficient & - \\
\hline$C_{D \alpha}$ & Induced drag coefficient & - \\
\hline$C_{L 0}$ & Lift coefficient at $\alpha=0$ & - \\
\hline$C_{L \alpha}$ & Lift coefficient dependent on $\alpha$ & - \\
\hline$m$ & Mass & $\mathrm{kg}$ \\
\hline$d$ & Diameter & $\mathrm{m}$ \\
\hline$\alpha$ & Angle of attack & $\mathrm{rad}$ \\
\hline$g$ & Acceleration due to gravity & $\mathrm{m} / \mathrm{s}^{2}$ \\
\hline & & \\
\hline
\end{tabular}




\section{REFERENCES}

Crowther, J.R. Potts and W.J. "Frisbee Aerodynamics." AIAA Applied Aerodynamics (2002).

Hummel, Sarah A. "Frisbee Flight in Simulation and Throw Biomechanics." Masters Thesis, University of California, Davis. (2003).

Larson, Ron. Calculus. Boston, MA: Houghton Mifflin Company, 2005.

Lidz, Franz. "Analyze Disk." Sports Illustrated (2002): 21.

Morrison, V.R. "The Physics of Frisbees." Electronic Journal of Classical Mechanics and Relativity, Mount Allison University. (2005).

Motoyama, Eugene. "The Physics of Flying Discs." (2002).

$<$ http://people.csail.mit.edu/jrennie/discgolf/physics.pdf $>$ 


\section{APPENDIX A - FIGURES}

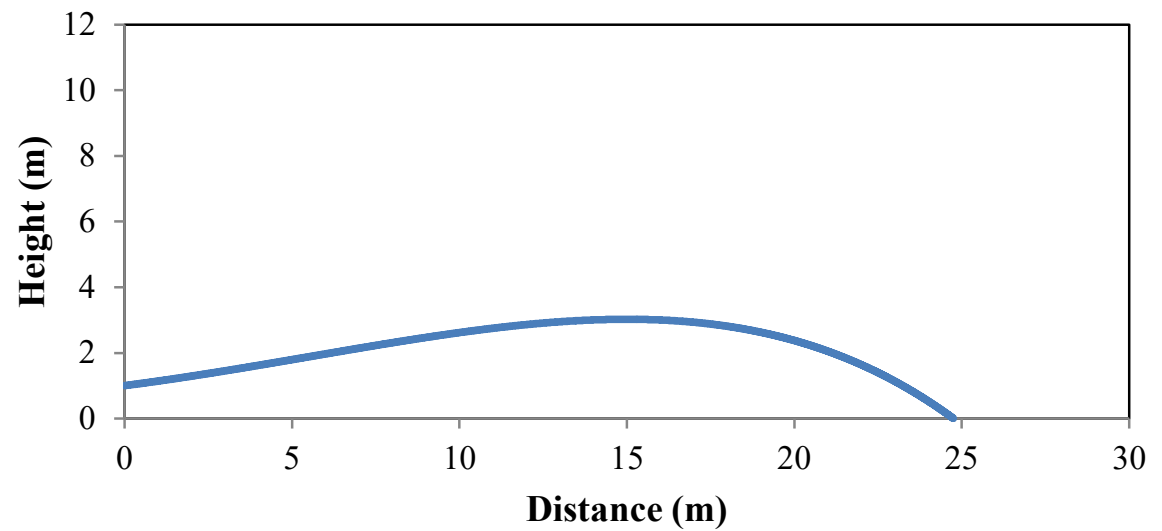

Figure 2A: Plot of height vs. distance for a Frisbee with initial velocity $14 \mathrm{~m} / \mathrm{s}$ and angle of attack $7.5^{\circ}$.

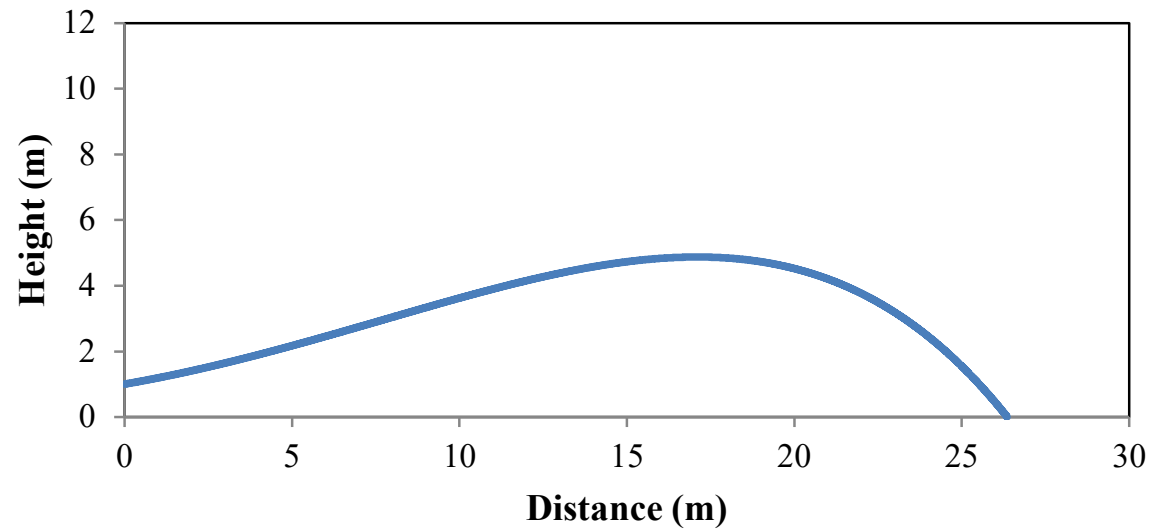

Figure 2B: Plot of height vs. distance for a Frisbee with initial velocity $14 \mathrm{~m} / \mathrm{s}$ and angle of attack $10^{\circ}$

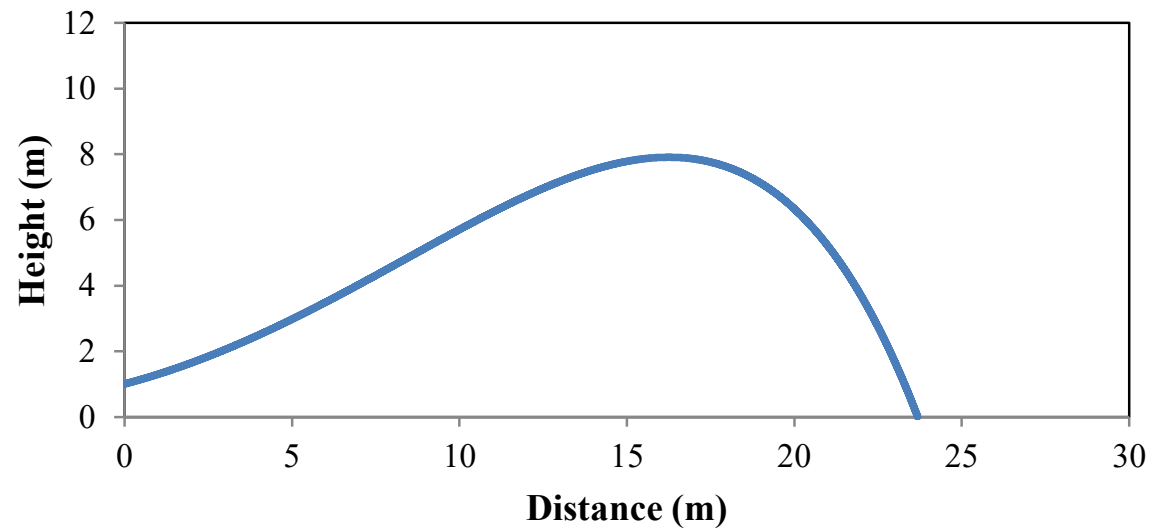

Figure 2C: Plot of height vs. distance for a Frisbee with initial velocity $14 \mathrm{~m} / \mathrm{s}$ and angle of attack $15^{\circ}$ 


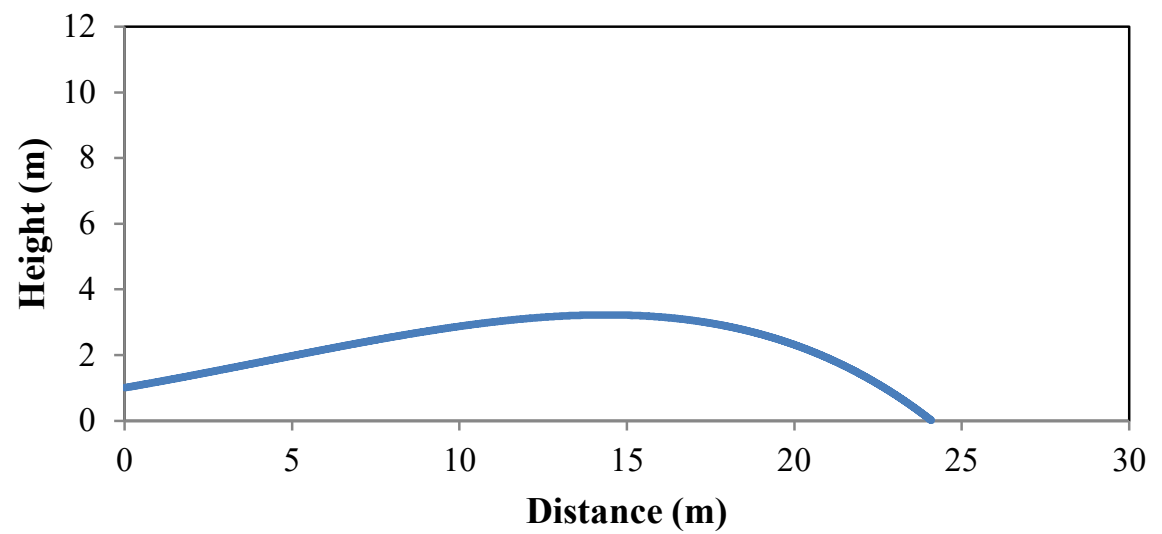

Figure 3A: Frisbee with initial velocity $14 \mathrm{~m} / \mathrm{s}$, angle of attack $10^{\circ}$ and diameter $0.22 \mathrm{~m}$

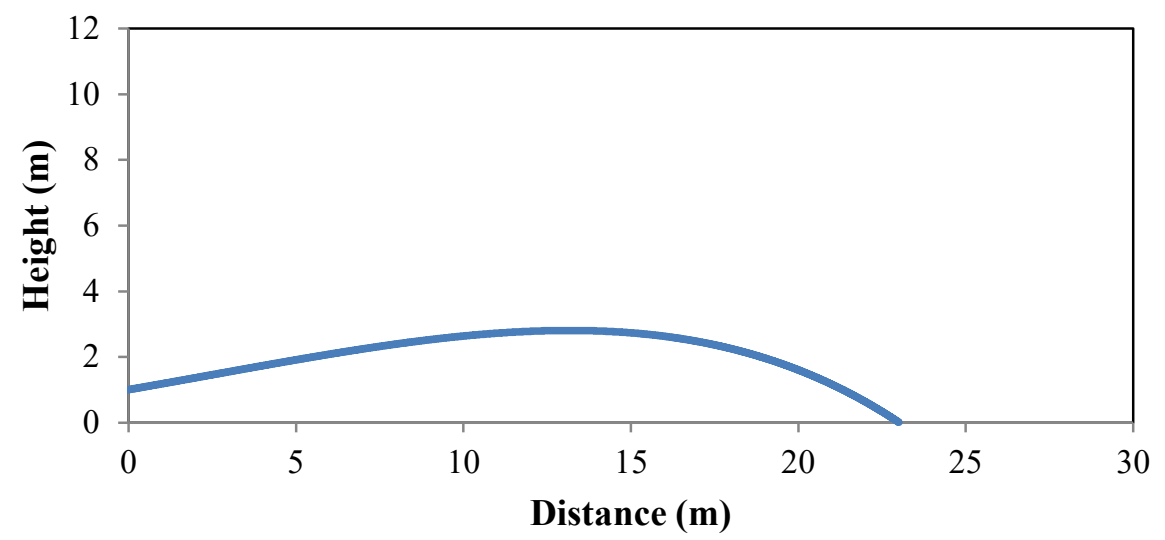

Figure 3B: Frisbee with initial velocity $14 \mathrm{~m} / \mathrm{s}$, angle of attack $10^{\circ}$ and diameter $0.24 \mathrm{~m}$

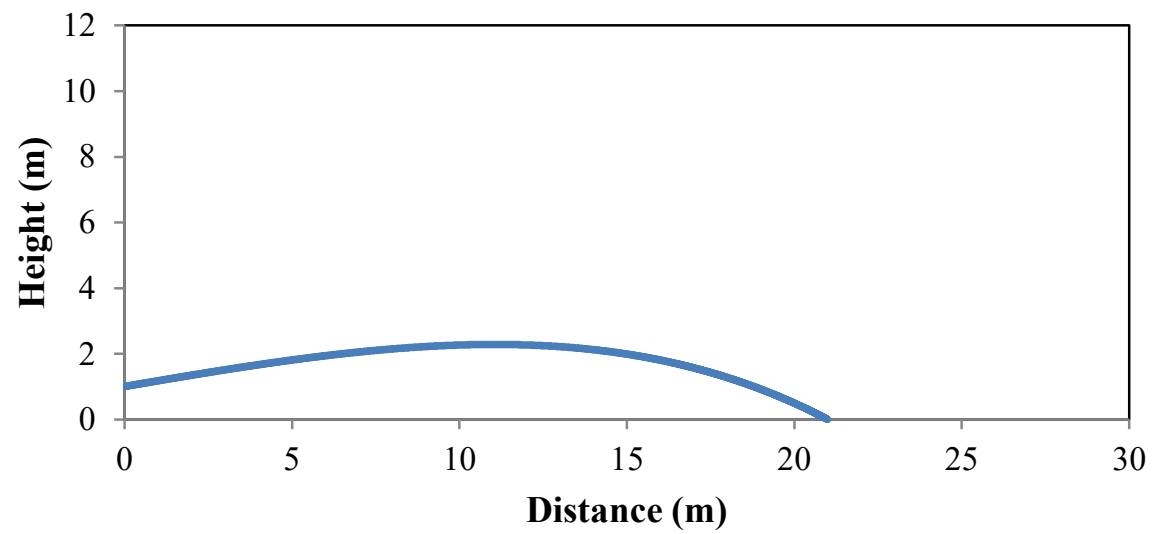

Figure 3C: Frisbee with initial velocity $14 \mathrm{~m} / \mathrm{s}$, angle of attack $10^{\circ}$ and diameter $0.28 \mathrm{~m}$ 


\section{APPENDIX B - TABLES}

\begin{tabular}{|clc|}
\hline Symbol & & Value \\
\hline$m$ & Mass of Frisbee & 0.175 \\
\hline$\rho$ & & 1.23 \\
\hline$g$ & Acceleration of gravity & $9.81 \mathrm{~m} / \mathrm{s}^{2}$ \\
\hline$d$ & Diameter of Frisbee & $0.26 \mathrm{~m}$ \\
\hline$A$ & Surface area of Frisbee & $\pi(d / 2)^{2}$ \\
\hline$v_{i}$ & Initial velocity & 14 \\
\hline$v_{x}$ & Initial velocity in the $x$ - direction & $v_{i} \cos \alpha$ \\
\hline$v_{y}$ & Initial velocity in the $y$ - direction & $v_{i} \sin \alpha$ \\
\hline$C_{D 0}$ & Frisbee dimensional constant* & 0.08 \\
\hline$C_{L 0}$ & Frisbee dimensional constant* & 0.15 \\
\hline$\alpha_{0}$ & Frisbee dimensional constant* & $-4 \pi / 180$ \\
\hline$C_{D \alpha}$ & Frisbee dimensional constant* & 2.72 \\
\hline$C_{L \alpha}$ & Frisbee dimensional constant* & 1.4 \\
\hline
\end{tabular}

Table 1: Parameter values used in the simulation. (* - See Hummel, 2003)

\begin{tabular}{|r|r|r|r|l|r|r|}
\hline $\mathrm{t}(\mathrm{s})$ & $\mathrm{v} \mathrm{x}(\mathrm{m} / \mathrm{s})$ & $\mathrm{v} \mathrm{y}(\mathrm{m} / \mathrm{s})$ & $\mathrm{x}(\mathrm{m})$ & $\mathrm{y}(\mathrm{m})$ & $\mathrm{vx}^{\prime}$ & $\mathrm{vy}^{\prime}$ \\
\hline 0 & 13.69 & 2.91 & 0 & 1 & -10.2147526 & 5.688679 \\
\hline 0.001 & 13.67979 & 2.915689 & 0.01369 & 1.002916 & -10.1995149 & 5.665559 \\
\hline 0.002 & 13.66959 & 2.921354 & 0.0273698 & 1.005837 & -10.1843112 & 5.642491 \\
\hline 0.003 & 13.6594 & 2.926997 & 0.0410394 & 1.008764 & -10.1691416 & 5.619474 \\
\hline 0.004 & 13.64923 & 2.932616 & 0.0546988 & 1.011697 & -10.1540058 & 5.596509 \\
\hline 0.005 & 13.63908 & 2.938213 & 0.068348 & 1.014635 & -10.1389037 & 5.573595 \\
\hline 0.006 & 13.62894 & 2.943786 & 0.0819871 & 1.017579 & -10.1238354 & 5.550732 \\
\hline 0.007 & 13.61882 & 2.949337 & 0.095616 & 1.020528 & -10.1088006 & 5.52792 \\
\hline 0.008 & 13.60871 & 2.954865 & 0.1092348 & 1.023483 & -10.0937993 & 5.505159 \\
\hline 0.009 & 13.59861 & 2.96037 & 0.1228435 & 1.026443 & -10.0788314 & 5.482448 \\
\hline
\end{tabular}

Table 2: Example of simulation spreadsheet for a Frisbee with initial velocity $14 \mathrm{~m} / \mathrm{s}$, angle of attack $12^{\circ}$ and diameter $0.26 \mathrm{~m}$. 